Buletin Ilmiah Mat. Stat. dan Terapannya (Bimaster)

Volume 09, No. 4 (2020), hal 541-548.

\title{
PERHITUNGAN DANA PENSIUN DENGAN METODE TRADITIONAI UNIT CREDIT (TUC) PADA TINGKAT SUKU BUNGA KONSTAN DAN MODEL VASICEK (Studi Kasus: Guru Honorer Kemenag di Kecamatan Kapuas)
}

\author{
Rizki Nur Rahmalita, Neva Satyahadewi, Setyo Wira Rizki
}

\begin{abstract}
INTISARI
Dana pensiun diandalkan oleh para karyawan untuk menunjang kesejahteraan hidup dimasa tua. Penelitian ini menerapkan tingkat suku bunga konstan dan model suku bunga stokastik untuk melakukan perhitungan program dana pensiun. Model suku bunga stokastik yang digunakan adalah model Vasicek. Berdasarkan rata-rata suku bunga tahunan BI, langkah awal perhitungan dimulai dengan mengestimasi parameter model Vasicek meliputi kecepatan tingkat suku bunga menuju titik keseimbangan, titik keseimbangan, dan volatilitas dengan metode maximum likelihood estimation (MLE). Tujuan penelitian ini adalah menganalisis perhitungan nilai iuran normal (NC) dan kewajiban aktuaria (AL) pada tingkat suku bunga konstan dan model Vasicek, dengan metode perhitungan dana pensiun traditional unit credit (TUC). Data yang digunakan adalah data guru honorer Kementerian Agama (Kemenag) di Kecamatan Kapuas, Kabupaten Sanggau dengan asumsi jumlah gaji per bulan tetap. Proporsi dari gaji yang disiapkan untuk manfaat pensiun sebesar 2,5\% dari total gaji peserta per tahun. Kesimpulan yang dihasilkan adalah pada suku bunga model Vasicek dihasilkan nilai NC dan AL yang lebih kecil sehingga cadangan manfaat pensiun yang disediakan instansi akan lebih kecil, begitu pula iuran normal yang harus dibayarkan peserta.
\end{abstract}

Kata Kunci: guru honorer, manfaat pensiun tetap, usia pensiun normal.

\section{PENDAHULUAN}

Pensiun merupakan masa dimana seorang pegawai sudah tidak lagi aktif bekerja baik karena sudah mencapai batas usia tertentu atau alasan-alasan lainnya. Undang-Undang Nomor 11 tahun 1992 menyebutkan bahwa batas usia pensiun normal adalah usia 55 tahun dan batas pensiun wajib maksimum adalah usia 60 tahun. Karena itulah dana pensiun berperan sebagai investasi jangka panjang bagi seseorang yang bekerja sehingga memiliki pegangan saat menghadapi masa pensiun. Menurut Otoritas Jasa Keuangan (OJK), bila merujuk kepada Undang-Undang Nomor 11 tahun 1992 tentang Dana Pensiun, bahwa Dana Pensiun adalah badan hukum yang mengelola dan menjalankan program yang menjanjikan manfaat pensiun.

Pelaksanaan asuransi dana pensiun di Indonesia terdiri dari dana pensiun pemberi kerja, dana pensiun lembaga keuangan, dan dana pensiun berdasarkan keuntungan. Sedangkan program dana pensiun terbagi lagi menjadi program pensiun manfaat pasti dan program pensiun iuran pasti. Program pensiun manfaat pasti adalah program pensiun yang manfaatnya ditetapkan dalam Peraturan Dana Pensiun atau program lain yang bukan merupakan program pensiun iuran pasti. Pensiun iuran pasti adalah program pensiun yang iurannya ditetapkan dalam Peraturan Dana Pensiun dan seluruh iuran serta hasil pengembangannya dibukukan pada rekening peserta sebagai manfaat pensiun. Program dana pensiun sebagai jaminan kesejahteraan dimasa tua menjadi suatu hal yang didambakan oleh para pegawai baik bagi yang bekerja di instansi pemerintah maupun swasta. Adanya program dana pensiun dapat menjadi sebuah motivasi bagi karyawan yang menyebabkan suasana kerja dan kualitas kerja menjadi lebih baik, yang pada akhirnya membantu dalam mencapai tujuan dengan lebih baik.

Kementerian Agama (Kemenag) merupakan salah satu kementerian pemerintah yang menaungi urusan agama, termasuk di dalamnya urusan madrasah. Pada Kemenag Sanggau, tepatnya di Kecama- 
tan Kapuas masih banyak guru honorer (guru non-PNS) yang mengajar disetiap madrasah. Gaji guru honorer biasa diperoleh dari dana BOS dan uang komite sekolah yang disesuaikan lagi dengan jam mengajar, sehingga sulit untuk mendapatkan jumlah yang besar. Kenyataan lain yang harus diterima oleh guru honorer adalah tidak memiliki investasi untuk kehidupan dimasa pensiun. Hal ini dikarenakan Kemenag Sanggau baru menyediakan dana pensiun bagi PNS.

Pada penelitian ini dilakukan simulasi perhitungan program dana pensiun bagi guru honorer dengan metode traditional unit credit (TUC). Perhitungan dilakukan pada tingkat suku bunga konstan dan suku bunga stokastik. Model Vasicek merupakan model suku bunga stokastik yang digunakan dalam penelitian ini. Penelitian difokuskan pada perbandingan hasil perhitungan iuran normal atau normal cost (NC) dan kewajiban aktuaria atau actuarial liability (AL) peserta, dengan memanfaatkan Tabel Mortalita Indonesia (TMI) 2011. Data yang digunakan adalah data guru honorer Kementerian Agama (Kemenag) di Kecamatan Kapuas, Kabupaten Sanggau berjumlah sebanyak 29 orang guru, dengan asumsi usia pensiun normal yaitu 60 tahun dan proporsi gaji untuk manfaat pensiun $(k)$ sebesar 2,5\% dari kumulatif gaji peserta dalam satu tahun.

\section{FUNGSI-FUNGSI DASAR AKTUARIA}

Fungsi dasar aktuaria merupakan fungsi yang digunakan dalam perhitungan dana pensiun meliputi:

1. Fungsi Tingkat Suku Bunga

Fungsi tingkat suku bunga digunakan untuk mendiskontokan pembayaran waktu yang akan datang ke waktu sekarang. Apabila $i$ adalah tingkat suku bunga, maka faktor diskonto pada tahun ke- $n$ adalah[1]:

$$
v^{n}=\frac{1}{(1+i)^{n}}
$$

\section{Fungsi Gaji}

Perhitungan dana pensiun dipengaruhi oleh besar gaji peserta setiap bulan. Besarnya gaji tahunan peserta yang berusia $t$ tahun dilambangkan dengan $s_{t}$ dan akumulasi gaji peserta selama memasuki usia pensiun dilambangkan dengan $S_{x}$ yang dapat dirumuskan sebagai berikut[1]:

$$
S_{x}=\sum_{t=y}^{x-1} s_{t}, \quad x \geq y
$$

3. Fungsi Manfaat

Fungsi manfaat digunakan untuk menentukan jumlah manfaat yang dibayarkan kepada peserta saat pensiun. Salah jenis fungsi manfaat adalah fungsi manfaat tetap atau flat dollar benefit dirumuskan sebagai berikut[1]:

$$
B_{x}=(x-y) b_{x}
$$

$B_{x}$ menyatakan total besar manfaat pensiun saat usia $x$ tahun, $x$ menyatakan usia peserta saat ini, $y$ menyatakan usia awal masuk kerja, dan $b_{x}$ menyatakan besar manfaat saat usia $x$ tahun dengan:

$$
b_{x}=k \cdot s_{x}
$$

$S_{x}=$ gaji tahunan peserta pada usia $x$ tahun

$k$ = proporsi dari gaji untuk manfaat pensiun

4. Fungsi Anuitas 
Anuitas merupakan rangkaian penerimaan atau pembayaran tetap yang dilakukan secara berkala dalam batas waktu tertentu. Fungsi anuitas dapat diperoleh dengan rumus berikut [1]:

$$
\ddot{a}_{r}=\sum_{n=0}^{\infty}{ }_{n} p_{x} v^{n}
$$

dengan $\ddot{a}_{r}$ merupakan anuitas hidup peserta saat usia pensiun dan ${ }_{n} p_{x}$ menyatakan peluang seseorang berusia $x$ tahun akan tetap hidup hingga mencapai usia $x+n$ tahun.

\section{METODE TRADITIONAL UNIT CREDIT}

Metode TUC biasa disebut juga unit credit cost method. Metode TUC sering digunakan pada dana pensiun dengan manfaat pensiun tetap dan pada metode ini tidak mengasumsikan skala gaji untuk gaji peserta pada tahun-tahun mendatang. Sehingga total besar manfaat pensiun pada usia $x$ dipengaruhi oleh besar manfaat saat usia $x$ tahun dikalikan dengan $(x-y)$. Pada metode TUC ini iuran normal yang dibayarkan oleh peserta guna memenuhi manfaat pensiun dinyatakan dengan $(N C)_{x}$ yang dirumuskan sebagai berikut [2]:

$$
(N C)_{x}=b_{x} v_{r-x}^{r-x} p_{x} \ddot{a}_{r}
$$

dengan:

$v^{r-x}=$ faktor diskonto pada saat usia pensiun $r$ dikurangi $x$ tahun

${ }_{r-x} P_{x}=$ merupakan peluang peserta berusia $x$ tahun akan tetap hidup hingga usia pensiun

Adapun kewajiban aktuaria atau sejumlah uang yang harus disediakan oleh penyelenggara untuk diberikan kepada peserta program dana pensiun, pada metode TUC dirumuskan sebagai berikut:

$$
(A L)_{x}=B_{x} v_{r-x}^{r-x} p_{x} \ddot{a}_{r}
$$

\section{MODEL VASICEK}

Model Vasicek pertama kali ditemukan oleh Oldrich Vasicek pada tahun 1977. Model Vasicek merupakan pemodelan pergerakan suku bunga yang cenderung kembali kepada tingkat suku bunga rata-rata atau titik keseimbangan $(\theta)$ setelah mengalami fluktuasi. Tingkat suku bunga model Vasicek diasumsikan mengikuti persamaan diferensial stokastik berikut [3]:

$$
d i_{t}=c\left[\theta-i_{t}\right] d t+\sigma d W_{u}
$$

Pada Persamaan (5) $c, \theta$, dan $\sigma$ adalah konstanta positif dengan $i_{t}$ tingkat suku bunga pada saat $t$, $i_{0}$ konstanta positif, koefisien $c$ menyatakan kecepatan tingkat bunga menuju titik keseimbangan, $\theta$ adalah titik keseimbangan, dan $\sigma$ adalah nilai volatilitas. Adapun $W_{u}$ menyatakan gerak Brown. Melalui Persamaan (5) yang diselesaikan dengan penyelesaian persamaan differensial parsial didapatkan persamaan berikut [4]:

$$
i_{t}=i_{0} e^{-c t}+\theta\left(1-e^{-c t}\right)+\sigma \int_{0}^{t} e^{-c(t-u)} d W_{u}
$$

Pada tahap estimasi parameter model Vasicek, nilai $c, \theta$, dan $\sigma$ diperoleh dengan metode MLE. Metode MLE memiliki kelebihan dapat menaksirkan nilai estimasi dengan lebih tepat. Fungsi kepadatan bersyarat untuk $i_{t}$ jika diketahui $i_{t-1}$ adalah:

$$
f\left(i_{t} \mid i_{t-1} ; \theta, c, \sigma\right)=\frac{1}{\sqrt{2 \pi \sigma^{2}}} \exp \left(\frac{-\left(i_{t}-i_{t-1} e^{-c \Delta t}-\theta\left(1-e^{-c \Delta t}\right)\right)^{2}}{2 \sigma^{2}}\right)
$$

Menggunakan Persamaan (6) dibentuk fungsi log-likelihood berikut. 


$$
\begin{aligned}
\ln L(\theta, c, \sigma) & =\sum_{t=1}^{n} \ln f\left(i_{t} \mid i_{t-1} ; \theta, c, \sigma\right) \\
& =-\frac{n}{2} \ln (2 \pi)-n \ln (\sigma)-\frac{1}{2 \sigma^{2}} \sum_{t=1}^{n}\left(i_{t}-i_{t-1} e^{-c \Delta t}-\theta\left(1-e^{-c \Delta t}\right)\right)^{2}
\end{aligned}
$$

Fungsi log-likelihood pada Persamaan (7) perlu dimaksimalkan dengan cara mencari turunan parsial dari persamaan tersebut dengan memperhatikan $c, \theta$, dan $\sigma$ yang menyebabkan semua persamaan disama dengankan nol. Sehingga diperoleh estimator-estimator sebagai berikut:

$$
\begin{aligned}
& \frac{\partial \ln L(\theta, c, \sigma)}{\partial \theta}=0 \quad \Rightarrow \quad \hat{\theta}=\frac{\sum_{t=1}^{n}\left(i_{t}-i_{t-1} e^{-c \Delta t}\right)}{n\left(1-e^{-c \Delta t}\right)} \\
& \frac{\partial \ln L(\theta, c, \sigma)}{\partial c}=0 \quad \Rightarrow \quad \hat{c}=-\frac{1}{\Delta t} \ln \left(\frac{\sum_{t=1}^{n}\left(i_{t}-\theta\right)\left(i_{t-1}-\theta\right)}{\sum_{t=1}^{n}\left(i_{t-1}-\theta\right)^{2}}\right) \\
& \frac{\partial \ln L(\theta, c, \sigma)}{\partial \sigma}=0 \quad \Rightarrow \quad \hat{\sigma}^{2}=\frac{1}{n} \sum_{t=1}^{n}\left(i_{t}-\theta-e^{-c \Delta t}\left(i_{t-1}-\theta\right)\right)^{2}
\end{aligned}
$$

Untuk memudahkan perhitungan selanjutnya maka dimisalkan persamaan berikut:

$$
\begin{gathered}
R_{x}=\sum_{t=1}^{n} i_{t-1} \quad ; \quad R_{x x}=\sum_{t=1}^{n} i_{t-1}^{2} ; \\
R_{y}=\sum_{t=1}^{n} i_{t} ; R_{y y}=\sum_{t=1}^{n} i_{t}^{2} ; R_{x y}=\sum_{t=1}^{n} i_{t-1} i_{t}
\end{gathered}
$$

$i_{t}$ menyatakan tingkat suku bunga pada waktu ke-t. Berdasarkan Persamaan (9) maka MLE dapat dihitung dengan:

$$
\begin{gathered}
\hat{\theta}=\frac{R_{y} R_{x x}-R_{x} R_{x y}}{n\left(R_{x x}-R_{x y}\right)-\left(R_{x}^{2}-R_{x y}\right)} \\
\hat{c}=-\frac{1}{\Delta t} \ln \left(\frac{R_{x y}-\theta\left(R_{x}+R_{y}\right)+n \theta^{2}}{R_{x x}-2 \theta R_{x}+n \theta^{2}}\right) \\
\sigma^{2}=\frac{2 c}{n\left(1-e^{-2 c \Delta t}\right)}\left(R_{y y}-2 e^{-c \Delta t} R_{x y}+e^{-2 c \Delta t} R_{x x}-2 \theta\left(1-e^{-c \Delta t}\right)\left(R_{y}-e^{-c \Delta t} R_{x}\right)+n \theta^{2}\left(1-e^{-c \Delta t}\right)^{2}\right)
\end{gathered}
$$

Tingkat suku bunga model Vasicek memengaruhi perhitungan nilai NC dan AL dana pensiun pada nilai faktor diskonto. Faktor diskonto untuk $i_{t}$ merupakan tingkat suku bunga pada tahun ke-t dihitung dengan persamaan berikut [1]:

$$
v_{\text {vasicek }}=\left(\frac{1}{\left(1+i_{1}\right)\left(1+i_{2}\right) \ldots\left(1+i_{n}\right)}\right)
$$

Maka untuk mencari nilai NC dan AL dari metode TUC menggunakan tingkat suku bunga model Vasicek dapat diperoleh dengan:

$$
\begin{aligned}
& (N C)_{x}=b_{x} v_{\text {vasicek } r-x}^{r-x} p_{x} \ddot{a}_{r_{\text {vasicek }}} \\
& (A L)_{x}=B_{x} v_{\text {vasicek } r-x}^{r-x} p_{x} \ddot{a}_{r_{\text {vasicek }}}
\end{aligned}
$$

Nilai $\ddot{a}_{r_{\text {vasicek }}}$ diperoleh dengan rumus sebagai berikut:

$$
\ddot{a}_{r_{\text {rasicek }}}=\sum_{k=0}^{r-x}{ }_{k} p_{x} v_{\text {vasicek }}^{k}
$$




\section{STUDI KASUS}

Pada penelitian ini digunakan data guru honorer Kementerian Agama di Kecamatan Kapuas, Kabupaten Sanggau. Jumlah data guru honorer adalah sebanyak 29 orang terdiri dari 11 orang lakilaki dan 18 orang perempuan. Data ini terdiri dari guru honorer di MIN Sanggau, MTSN 1 Sanggau, dan MAN Sanggau. Rentang usia saat ini dari guru honorer adalah antara usia 23 tahun hingga 43 tahun. Jumlah gaji per bulan berada pada rentang Rp360.000 sampai dengan Rp1.568.000. Sistem pemberian gaji terhadap guru honorer bersifat tetap atau tidak terjadi kenaikan gaji dari mulai masuk kerja hingga usia saat ini. Rata-rata usia masuk kerja dari guru honorer adalah 25 tahun dan rata-rata usia guru honorer saat ini adalah 30 tahun. Adapun rata-rata penghasilan guru honorer setiap bulannya adalah sekitar Rp1.133.724. Asumsi dan ketentuan yang digunakan dalam perhitungan dana pensiun dengan metode TUC pada suku bunga konstan dan model suku bunga Vasicek dalam penelitian ini, yaitu:

1. Seluruh peserta mengikuti program pensiun mulai tahun 2020 dengan usia pensiun normal $(r)$ 60 tahun.

2. Menggunakan asumsi menfaat tetap dengan proporsi gaji untuk manfaat pensiun $(k)$ sebesar 2,5\% dari kumulatif gaji per tahun $\left(s_{x}\right)$. Nilai ini diambil berdasarkan undang-undang nomor 11 tahun 1969 tentang Pensiun Pegawai Negeri Sipil.

3. Sesuai kebjiakan Kementerian Agama Kabupaten Sanggau diasumsikan tidak terjadi kenaikan gaji bagi peserta hingga usia pensiun.

4. Tingkat suku bunga konstan ditetapkan 5,83\% per tahun.

\section{Estimasi Parameter Model Vasicek}

Peserta Nomor 15 dari data penelitian yang digunakan, dipilih sebagai contoh perhitungan untuk menjelaskan persoalan yang dibahas. Diketahui peserta Nomor 15 berjenis kelamin laki-laki, mulai bekerja pada usia 22 tahun dan saat ini berusia 36 tahun, serta besar gaji setiap bulan tetap yaitu sebesar Rp1.200.000. Estimasi parameter model Vasicek dihitung berdasarkan nilai BI rate per tahun dari tahun 2009 sampai tahun 2019 sebagai berikut.

Tabel 1 BI Rate per Tahun

\begin{tabular}{ccc|ccc}
\hline Tahun & $t$ & BI rate $\left(i_{t}\right)$ & Tahun & $t$ & BI rate $\left(i_{t}\right)$ \\
\hline 2009 & 0 & $7,15 \%$ & 2015 & 6 & $7,52 \%$ \\
2010 & 1 & $6,50 \%$ & 2016 & 7 & $6,00 \%$ \\
2011 & 2 & $6,58 \%$ & 2017 & 8 & $4,56 \%$ \\
2012 & 3 & $5,77 \%$ & 2018 & 9 & $5,10 \%$ \\
2013 & 4 & $6,48 \%$ & 2019 & 10 & $5,83 \%$ \\
2014 & 5 & $7,54 \%$ & & & \\
\multicolumn{5}{l}{ Sumber: Badan Pusat Statistik }
\end{tabular}

Penentuan nilai estimasi parameter perlu dilakukan sebelum melakukan perhitungan dana pensiun dengan suku bunga model Vasicek. Berdasarkan Tabel 1 dicari estimasi parameter $c, \theta$, dan $\sigma$ dengan metode MLE dan dihasilkan nilai estimasi parameter yaitu: titik keseimbangan sebesar $\theta=0,0277$, kecepatan tingkat bunga menuju titik keseimbangan sebesar $c=2,0486$, dan volatilitas sebesar $\sigma=0,0640$. Berdasarkan nilai estimasi parameter model Vasicek yang diperoleh dan nilai $i_{0}=5,83 \%$, disimulasikan nilai $i_{t}$ untuk 40 tahun mendatang pada model Vasicek dengan software $\mathrm{R}$ dan diperoleh hasil sebagai berikut. 
Tabel 2 Simulasi Nilai $i_{t}$ Model Vasicek

\begin{tabular}{cc}
\hline$n$ & $i_{t}$ \\
\hline 1 & $4,63 \%$ \\
2 & $5,00 \%$ \\
3 & $5,66 \%$ \\
4 & $5,45 \%$ \\
$\vdots$ & $\vdots$ \\
38 & $1,70 \%$ \\
39 & $1,73 \%$ \\
40 & $2,35 \%$ \\
\hline
\end{tabular}

Langkah selanjutnya, dibentuk tabel fungsi gaji yang menampilkan usia peserta Nomor 15 saat ini, gaji peserta pada usia $x$ tahun serta kumulatif gaji peserta dari tahun ke tahun. Diketahui gaji bulanan peserta nomor 15 adalah sebesar Rp1.200.000 dan diasumsikan tidak terjadi kenaikan gaji hingga usia pensiun. Maka:

\begin{tabular}{ccc}
\multicolumn{3}{c}{ Tabel 3 Fungsi Gaji } \\
\hline$x$ & $S_{x}$ & $S_{x}$ \\
\hline 36 & Rp14.400.000 & Rp201.600.000 \\
37 & Rp14.400.000 & Rp216.000.000 \\
$\vdots$ & $\vdots$ & $\vdots$ \\
59 & Rp14.400.000 & Rp532.800.000 \\
60 & 0 & Rp547.200.000 \\
\hline
\end{tabular}

Berdasarkan Tabel 3 diketahui bahwa pada usia pensiun normal yaitu 60 tahun, nilai $s_{60}=0$ (karena sudah memasukui usia pensiun) dan kumulatif gaji tahunan peserta nomor 15 sebesar Rp547.200.000.

Setelah fungsi gaji, dibentuk tabel fungsi manfaat yang menampilkan besar manfaat pada usia $x$ tahun dan akumulasi besar manfaat pensiun saat memasuki usia $x$ tahun. Perhitungan dilakukan dengan menggunakan Persamaan (1) dan (2) sebagai berikut:

Tabel 4 Fungsi Manfaat

\begin{tabular}{ccc}
\hline$x$ & $b_{x}$ & $B_{x}$ \\
\hline 36 & $\mathrm{Rp} 360.000$ & $\mathrm{Rp} 5.040 .000$ \\
37 & $\mathrm{Rp} 360.000$ & $\mathrm{Rp} 5.400 .000$ \\
$\vdots$ & $\vdots$ & $\vdots$ \\
59 & $\mathrm{Rp} 360.000$ & $\mathrm{Rp} 13.320 .000$ \\
60 & 0 & 0 \\
\hline
\end{tabular}

Berdasarkan Tabel 4 diketahui pada usia pensiun normal 60 tahun, nilai $b_{60}=0$ dan $B_{60}=0$ hal ini karena nilai-nilainya dipengaruhi oleh besar gaji bulanan peserta, dan pada usia 60 tahun peserta sudah memasuki usia pensiun.

\section{Nilai Anuitas Hidup}

Menggunakan TMI 2011 dan data peserta Nomor 15 dilakukan perhitungan anuitas hidup pada suku bunga konstan dan model Vasicek. Perhitungan dimulai dengan menyusun Tabel 4 dengan kolom pertama berisikan masa kerja $(n)$, kolom kedua diisi dengan usia $(x)$, kolom ketiga diisi dengan peluang meninggal seseorang berusia $x$ tahun $\left(q_{x}\right)$, dan kolom keempat diisi dengan peluang hidup seseorang berusia $x$ tahun. Diketahui peserta nomor 15 mulai masuk kerja pada usia 22 tahun dengan usia pensiun normal 60 tahun. Maka pada kolom kelima Tabel 5 diisi dengan peluang hidup peserta 
Nomor 15 dari usia masuk kerja hingga $n$ tahun mendatang $\left({ }_{n} p_{22}\right)$, dengan perhitungan sebagai berikut:

$$
\begin{aligned}
& n=0 \rightarrow{ }_{0} p_{22}=1 \\
& n=1 \rightarrow{ }_{1} p_{22}=0,9993 \\
& n=2 \rightarrow{ }_{2} p_{22}={ }_{1} p_{22} \times{ }_{1} p_{23}=0,9985 \\
& \vdots \\
& n=38 \rightarrow{ }_{38} p_{22}={ }_{1} p_{22} \times{ }_{1} p_{23} \times \cdots \times{ }_{1} p_{37}=0,8721
\end{aligned}
$$

Selanjutnya, kolom keenam diisi dengan faktor diskonto pada suku bunga konstan dengan $i_{0}=5,83 \%$ perhitungannya sebagai berikut:

$$
\begin{aligned}
& v_{\text {konstan }}^{0}=\left(\frac{1}{1+0,0583}\right)^{0}=1,0000 \\
& v_{\text {konstan }}^{1}=\left(\frac{1}{1+0,0583}\right)^{1}=0,9449 \\
& \vdots \\
& v_{\text {konstan }}^{38}=\left(\frac{1}{1+0,0583}\right)^{38}=0,1161
\end{aligned}
$$

Dilanjutkan dengan kolom ketujuh, diisi dengan nilai faktor diskonto pada model suku bunga Vasicek dengan $i_{0}=5,83 \%$. Faktor diskonto pada model Vasicek dihitung dengan nilai $i_{t}$ hasil simulasi pada Tabel 2 sebagai berikut:

$$
\begin{aligned}
& v_{\text {vasicek }}^{0}=1,00000 \\
& v_{\text {vasicek }}^{1}=\left(\frac{1}{(1+0,04634)}\right)=0,95571 \\
& \vdots \\
& v_{\text {vasicek }}^{38}=\left(\frac{1}{(1+0,04634)(1+0,04996) \ldots(1+0,00727)}\right)=0,09955
\end{aligned}
$$

Kolom kedelapan dan kesembilan pada Tabel 5 masing-masing diiisi dengan nilai $v_{\text {konstan }}^{n} \times_{n} p_{22}$ dan nilai $v_{\text {vasicek }}^{n} \times{ }_{n} p_{22}$.

Tabel 5 Perhitungan Anuitas Hidup

\begin{tabular}{ccccccccc}
\hline$n$ & $x$ & $q_{x}$ & $p_{x}$ & ${ }_{n} p_{22}$ & $v_{\text {konstan }}^{n}$ & $v_{\text {vasicek }}^{n}$ & $v_{\text {konstan }}^{n} \times{ }_{n} p_{22}$ & $v_{\text {vasicek }}^{n} \times{ }_{n} p_{22}$ \\
\hline 0 & 22 & 0,0007 & 0,9993 & 1,0000 & 1,0000 & 1,0000 & 1,0000 & 1,0000 \\
1 & 23 & 0,0008 & 0,9992 & 0,9993 & 0,9449 & 0,9557 & 0,9443 & 0,9551 \\
2 & 24 & 0,0008 & 0,9992 & 0,9985 & 0,8929 & 0,9102 & 0,8916 & 0,9089 \\
$\vdots$ & $\vdots$ & $\vdots$ & $\vdots$ & $\vdots$ & $\vdots$ & $\vdots$ & $\vdots$ & $\vdots$ \\
37 & 59 & 0,0132 & 0,9868 & 0,8837 & 0,1229 & 0,1003 & 0,1086 & 0,0886 \\
38 & 60 & 0,0142 & 0,9858 & 0,8721 & 0,1161 & 0,0995 & 0,1013 & 0,0868 \\
\hline
\end{tabular}

Berdasarkan hasil pada Tabel 5 diperoleh anuitas hidup pada suku bunga konstan berikut:

$$
\ddot{a}_{r_{\text {konstan }}}=\sum_{n=0}^{38} v_{\text {konstan } n}^{n} p_{x}=15,8980
$$


Selanjutnya anuitas hidup pada model suku bunga Vasicek diperoleh sebagai berikut:

$$
\ddot{a}_{r_{\text {vasicek }}}=\sum_{n=0}^{38} v_{\text {vasicek }}^{n} p_{x}=14,9642
$$

\section{Normal Cost (NC) dan Actuarial Liability (AL)}

$\mathrm{NC}$ adalah sejumlah uang yang dibayarkan oleh peserta guna memenuhi manfaat pensiun. AL adalah sejumlah uang yang disediakan oleh penyelenggara untuk diberikan kepada peserta program dana pensiun. Berdasarkan Persamaan (3) dan (4) serta Persamaan (9) dan (10) dihitung nilai NC dan AL pada suku bunga konstan dan model Vasicek. Hasil yang diperoleh sebagai berikut:

Tabel 6 Perhitungan Nilai NC dan AL Peserta Nomor 15

\begin{tabular}{ccrrrr}
\hline$x$ & $n$ & $(N C)_{x}$ konstan & $(A L)_{x}$ konstan & $(N C)_{x}$ vasicek & $(A L)_{x}$ vasicek \\
\hline 0 & 22 & Rp579.506 & Rp0 & Rp467.666 & Rp0 \\
1 & 23 & Rp613.715 & Rp613.715 & Rp471.389 & Rp471.389 \\
2 & 24 & Rp649.995 & Rp1.299.989 & Rp478.201 & Rp956.402 \\
$\vdots$ & $\vdots$ & $\vdots$ & $\vdots$ & $\vdots$ & $\vdots$ \\
36 & 58 & Rp4.980.383 & Rp179.293.795 & Rp4.779.111 & Rp172.047.993 \\
37 & 59 & Rp5.336.485 & Rp197.449.946 & Rp5.080.461 & Rp187.977.064 \\
38 & 60 & Rp0 & Rp0 & Rp0 & Rp0 \\
\hline
\end{tabular}

Berdasarkan Tabel 6 diketahui pada suku bunga konstan, apabila peserta Nomor 15 pensiun pada usia 60 tahun maka NC yang dibayarkan oleh peserta adalah sebesar Rp5.336.485. Nilai AL yang dibayarkan oleh pihak penyelenggara adalah sebesar Rp197.449.946. Pada model Vasicek, apabila peserta Nomor 15 pensiun pada usia 60 tahun maka membayarkan NC sebesar Rp5.080.461. Nilai AL yang dibayarkan oleh pihak penyelenggara adalah sebesar Rp187.977.064.

\section{PENUTUP}

Hasil perhitungan pada suku bunga konstan sebesar 5,83\% dihasilkan nilai NC dan nilai AL yang lebih besar, dibandingkan pada suku bunga model Vasicek dengan $i_{0}$ sebesar 5,83\%. Jika Kemenag Sanggau berencana menerapkan program dana pensiun bagi guru honorer, maka penggunaan suku bunga model Vasicek menyebabkan cadangan manfaat pensiun yang disediakan Kemenag akan lebih kecil, begitu pula iuran normal yang harus dibayarkan peserta.

\section{DAFTAR PUSTAKA}

[1]. Winklevoss, H. E. Pension Mathematics with Numerical Illustrations. Ed ke-2. Pension Research Council; 1993.

[2]. Aitken, W. H. A Problem Solving Approach to Pension Funding and Valuation. Ed ke-2, Winsted: ACTEX Publications; 1994.

[3]. Brigo, D. dan Mercurio, F. Interest Rate Models-Theory and Practice: With Smile, Inflation and Credit. Springer Berlin Heidelberg; 2006.

[4]. Sypkens, R. Risk Properties and Parameter Estimation on Mean Reversion and GARCH Models. University of South Africa (Thesis); 2010.

RIZKI NUR RAHMALITA $\quad$ : Jurusan Matematika FMIPA UNTAN, Pontianak rizkiraamalita@gmail.com

NEVA SATYAHADEWI : Jurusan Matematika FMIPA UNTAN, Pontianak neva.satya@math.untan.ac.id

SETYO WIRA RIZKI $\quad$ : Jurusan Matematika FMIPA UNTAN, Pontianak setyo.wirarizki@math.untan.ac.id 